\title{
Novel Molding Method and Enhanced Cell Homogeneity in the Powder Metallurgical Route for Production of Closed Cell Al-Foam
}

\author{
A.T. ERTURK ${ }^{a, *}$ AND T. SAHIN ${ }^{b}$ \\ ${ }^{a}$ Kocaeli University, Ford Otosan Ihsaniye Vocational School of Automotive, Kocaeli, Turkey \\ ${ }^{b}$ Kocaeli University, Mechanical Eng. Dept., Kocaeli, Turkey
}

\begin{abstract}
$\mathrm{TiH}_{2}$ content, mixing, pressing, different mold filling rate as the factors which affect foaming process on the powder metallurgical route were investigated. $\mathrm{TiH}_{2}$ was added in the amount of $0.5-1-1.5-2$ wt\% to adjust the proper amount. Differential scanning calorimetry tests were conducted on the $\mathrm{TiH}_{2}$ powders in order to obtain optimum hydrogen releasing condition. Aluminum and $\mathrm{TiH}_{2}$ powders were blended with the different speedtime combination. The mix was compacted at different pressures with the aim of explaining of the oxide layer deformation. An acceptance-rejection criterion was developed and used in pore analysis. Also, the using of a borosilicate glass molding technique are completely original and a new approach.
\end{abstract}

DOI: 10.12693/APhysPolA.131.39

PACS/topics: 81.05.Rm, 82.33.Ln, 61.43.Gt, 61.05.cp, 68.37.Hk

\section{Introduction}

Metallic foams are a new different material group with unfamiliar special abilities on mechanical, thermal, electric, and acoustic characteristics such as high strength to weight ratios, excellent impact energy absorption, high specific stiffness which make them very attractive for use in the industry $[1,2]$. Various process-routes have been developed to make metal foams, each of which depends on the state of the metal (solid, liquid, gaseous, or ionized) [2]. Metal powders are the starting materials at the powder metallurgical (PM) route, which the actual foaming takes place in the liquid state when the blowing agent decomposes under the influence of heat and releases gas. Titanium hydride $\left(\mathrm{TiH}_{2}\right)$ is used as a foaming agent in various commercial and the laboratory applications, which decomposes below the melting point of many light metals. In the PM route, metal powders are mixed with $\mathrm{TiH}_{2}$, after then compacted to yield a dense precursor and lastly foamed in a furnace [2-4].

The properties of metal foam depend on morphological features such as cell wall curvature, pore size, shape and distribution, etc. [3-5]. In order to make the production process more reliable and reproducible, the use of space-holder materials in PM processing route is being widely used for its capability to produce fairly uniform metal foams, and commercially cost-effective compared with the other methods [6, 7]. Various studies [5-7] were carried out using aluminum foams, in particular for commercial production samples. Multiaxial tests were reported by Sridhar and Fleck [5] for closed cell Alulight foam. Zettl et al. [6] investigated the fatigue properties under

*corresponding author; e-mail: tamererturk@gmail.com fully reversed loading condition of Alulight foams and reported their fatigue damage process. The structural response of Shunk and Alulight foam sandwiches under static and dynamic loading were investigated by Crupi and Montanini [7].

Furthermore, several papers [8-11] are available in the literature on the foam formation. Some of them $[10,11]$ are about mechanical, thermal, electrical properties of the product. During the last decade, most research $[11,12]$ focused on compressive strength test. The mismatch between the decomposition temperature of the $\mathrm{TiH}_{2}$ and the melting point of the pure metal or its alloy is the biggest problem in the PM process. A group of researchers $[13,14]$ has focused on overcoming this problem. Some experimental papers have been published on the kinetics of hydrogen release [14]. When $\mathrm{TiH}_{2}$ is heat-treated under an air atmosphere, an oxide layer is formed on the surface of the particles $[13,14]$. Basically, it is very crucial to investigate the effective factors on the PM process. The distribution of cell sizes and shapes exhibits a certain randomness which is typical for the PM foaming process. Inhomogeneity of metallic foams which are produced by PM method arises from foaming process limits. The aim of the present work is to find out optimum values of the $\mathrm{TiH}_{2}$ content, mixing and pressing parameters in order to obtain more homogeneous aluminum foams with PM route.

\section{Experimental procedure}

$\mathrm{Al}$ foams were produced using $\mathrm{Al}$ and $\mathrm{TiH}_{2}$ powders (supplied by Alfa Aesar) with purity of $99.5 \%$ and $99 \%$, respectively, and with grain sizes all less than $50 \mu \mathrm{m}$. As-received $\mathrm{TiH}_{2}$ powder was heated isothermally from room temperature up to various temperatures $\left(450,500\right.$, and $\left.550{ }^{\circ} \mathrm{C}\right)$ with a heating rate of $10^{\circ} \mathrm{C} / \mathrm{min}$ for $180 \mathrm{~min}$. The $\mathrm{TiH}_{2}$ powders were characterized 
as-received and after the heat-treatments by differential scanning calorimeter (DSC). DSC analysis was performed from 25 to $750{ }^{\circ} \mathrm{C}$ in an argon atmosphere at a purge rate of $50 \mathrm{ml} / \mathrm{min}$ with a heating rate of $10^{\circ} \mathrm{C} / \mathrm{min}$ using an $\mathrm{Al}_{2} \mathrm{O}_{3}$ crucible with a lid, and the sample sizes were approximately $80 \mathrm{mg}$. The mixing parameter researches were carried out by using the following methodologies to analyze the conditions of the best distributions as a function of mixing time and speed. The $\mathrm{TiH}_{2}$ powder was mixed with specified amounts of aluminum powders to reach the targeted composition. After the mixing processes optical microscope (OM) images were taken with $100 \times$. The distributions of average particle size, the aspect ratio and the distribution ratio of $\mathrm{TiH}_{2}$ particles were analyzed and graphically illustrated by the Clamex-Captiva image capturing and measuring software. The foaming aluminum is fabricated in the following stages: 1 - heat treatment of the $\mathrm{TiH}_{2}, 2$ - mixing powders, 3 - first pressing (cold), 4 - second pressing (cold), 5-pressing (hot) simultaneously induction heating, 6 - holding in a furnace. The apparatus used in the manufacture can be seen in Fig. 1. The borasilicate glass molding system was combined between two plates with threaded rod by screwing.

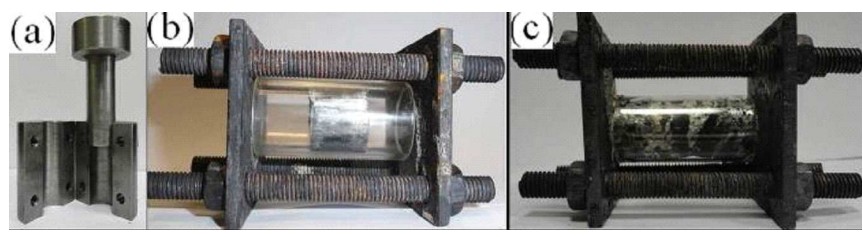

Fig. 1. The apparatus (a) pressing die, (b) borosilicate glass molding, (c) foaming in the glass molding.

\section{Results and discussion}

$\mathrm{TiH}_{2}$ powders were analyzed by DSC in the argon atmosphere. The DSC traces in Fig. 2a show hydrogen evolution from the $\mathrm{TiH}_{2} \rightarrow \mathrm{Ti}+\mathrm{H}_{2}$ reaction. The decomposition process of the untreated powder was observed in two overlapping endothermic stages. The starting points of the endotherms were found approximately at $420^{\circ} \mathrm{C}$ for the first and $580^{\circ} \mathrm{C}$ for the second one. The desorption process was nearly complete at $750^{\circ} \mathrm{C}$. The first endotherm got weak in the trace of heat-treated powder at $450{ }^{\circ} \mathrm{C}$ that disappeared at 500 and $550^{\circ} \mathrm{C}$. Also, heat treatments to 500 and $550^{\circ} \mathrm{C}$ resulted in delays in hydrogen evolution. XRD patterns for $\mathrm{TiH}_{2}$ powders to different temperatures are shown in Fig. 2b. The untreated powder was found to be single phase. After the heat threatening in air, the peaks corresponding to $\mathrm{TiH}_{x}$ and also $\mathrm{Ti}_{3} \mathrm{O}$ and $\mathrm{TiO}_{2}$ were detected.

Precursors were placed in a pre-heated oven at $800^{\circ} \mathrm{C}$, and temperatures were recorded simultaneously via a thermocouple positioned in the sample. Graphical displays of this data can be shown in Fig. 2c. It can be understood from the curves that foam formation process seems to be taking place around $652.5^{\circ} \mathrm{C}$. Additionally,

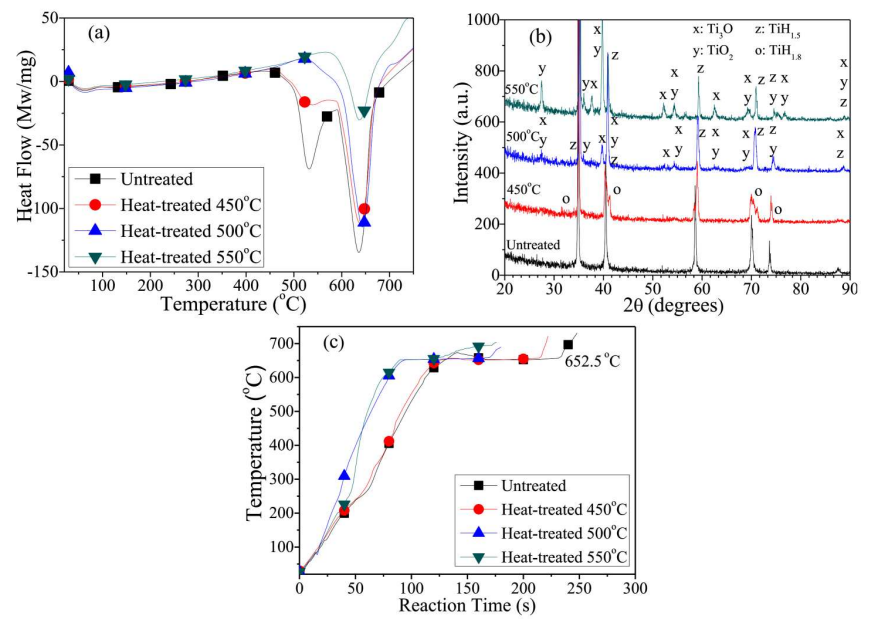

Fig. 2. (a) DSC traces, (b) XRD patterns, (c) reaction curves.

linear increase in temperature was realized on samples into the oven from room temperature to the reaction temperature. The reaction time was the longest for untreated sample. The reaction time was gradually shortened when raising the treatment temperature. Due to the two endothermic reaction step in untreated sample, the process took longer time than others. On the other hand, the first hydrogen release reaction started to decrease at $450{ }^{\circ} \mathrm{C}$ and almost entirely lost at 500 and $550^{\circ} \mathrm{C}$ treatment temperatures. The process was shorter than untreated sample, because the only second step reaction left. According to the analysis of the reaction, providing stability and homogeneity of the foam become difficult for untreated sample due to the intensive two-stage $\mathrm{H}_{2}$ release reaction. When applied to the heat treatment temperature of $550{ }^{\circ} \mathrm{C}$, due to the absence of the first reaction stage linear increase in temperature continued until the time of the second reaction stage. The DSC measurements confirmed this behavior that the only second step of the reaction was seen at the range of $600-700{ }^{\circ} \mathrm{C}$ on the curves. According to these findings, if heat treatment is applied at $550^{\circ} \mathrm{C}$, the release of hydrogen on the foaming process will become unstable. As a result of analyses performed on $\mathrm{TiH}_{2}$ to achieve structural stability, heat treatment should be performed in the range of $450-500^{\circ} \mathrm{C}$.

Regular mixing is a factor affecting the foam product directly. To analyze the conditions of the best distribution, $\mathrm{Al}$ powder was mixed with $1 \mathrm{wt} \% \mathrm{TiH}_{2}$ particles at different rotational speeds (22.4-45-63 and $90 \mathrm{rpm})$ and periods (30-60-90-120 min). The aspect ratio of $\mathrm{TiH}_{2}$ particles distribution and dimensional analysis were performed separately on each cross-sectional surface of mixtures with OM images. Although severe limitation of optical microscopy is its small depth of focus, microscopic analyses are the only method in which the each particle is measured.

The graph in Fig. 3a shows change in the average grain size depending on different mixing process variables. 


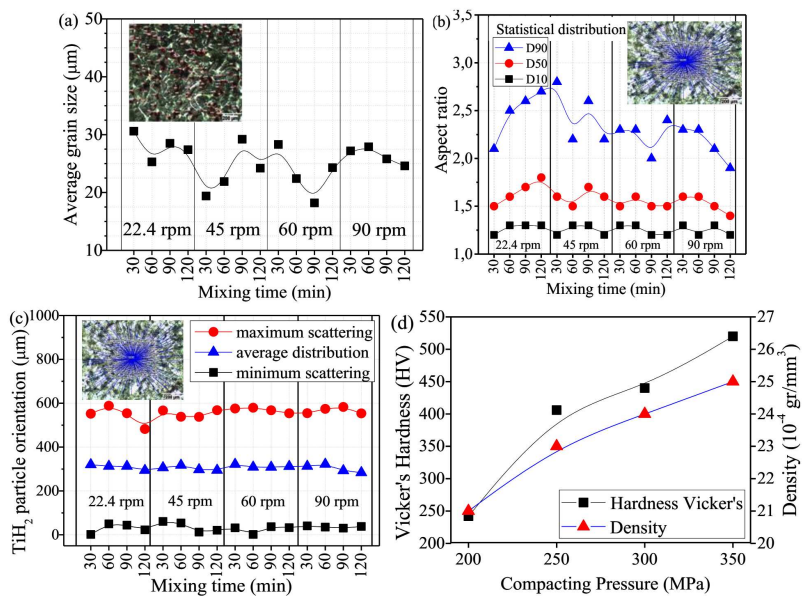

Fig. 3. (a) grain size changes, (b) statistical distribution of aspect ratio vs. mixing-type, (c) $\mathrm{TiH}_{2}$ orientation, (d) hardness and density values after compaction.

Average grain size showed a distribution in the range 32 to $18 \mathrm{\mu m}$ and together with the average value of distributions $25 \mu \mathrm{m}$. The homogeneous particle size is required to be identified according to the mixing process variables.

It was necessary to select a mixing type in Fig. 3b. Selective parameters were $90 \mathrm{rev} / \mathrm{min}$ stirring rate and 90 or 120 min mixing time for homogeneous particle size.

The analysis of particle orientation versus mixing-type was given in Fig. 3c. The maximum and minimum values were proved that low-speed mixing caused irregularity in the distribution. On the contrary, irregularity disappeared at 60 and $90 \mathrm{rev} / \mathrm{min}$. It was selected as a mixing parameter that D10 and D90 values were as close as possible. When the statistical distribution of the aspect ratio was examined at the $90 \mathrm{rpm}$ stirring rate, both of 90 and 120 min mixing times gave the desired result. In further step, powder mix pressed by cold uni-axial compaction in a $20 \mathrm{~mm}$ diameter steel die to a pressure of $200,250,300$, and $350 \mathrm{MPa}$ (upload rate $1 \mathrm{kN} / \mathrm{s}$ ) for $600 \mathrm{~s}$. Obtained compact at the first pressing was turned upside down in the die and second pressing was performed with the same conditions as first pressing. After cold compression, obtained green precursors were pressed under $250 \mathrm{MPa}$ and simultaneously heated by an induction heater at $30{ }^{\circ} \mathrm{C}$. Then Vickers's hardness and density of the pressed samples were measured to reveal level of the oxide layer deformation.

The level of hardness and density showed increasing trend that is compatible to each other as expected result with increase of compaction pressure (in Fig. 3d). Therefore, the most appropriate pressing value is $350 \mathrm{MPa}$ for oxide layer deformation and precursor production. After determining suitable values of the effective parameters, metallic foams were produced with different mold filling portion.

Rejected pore values were defined bigger than 2, and the others were considered as acceptable pores in Fig. 4a. Results of the pore circularity calculations were addressed in two categories as rejected pores or acceptable pores. Normally circularity value is ranged from 0 to 1 , and the best circular state is 1 . It was understood that quantities of total and rejected pores tend to increase with mold filling rate from 40 to $80 \%$. Furthermore, in the case where the mold fill rate was $60 \%$, the accepted number of pores were the highest.
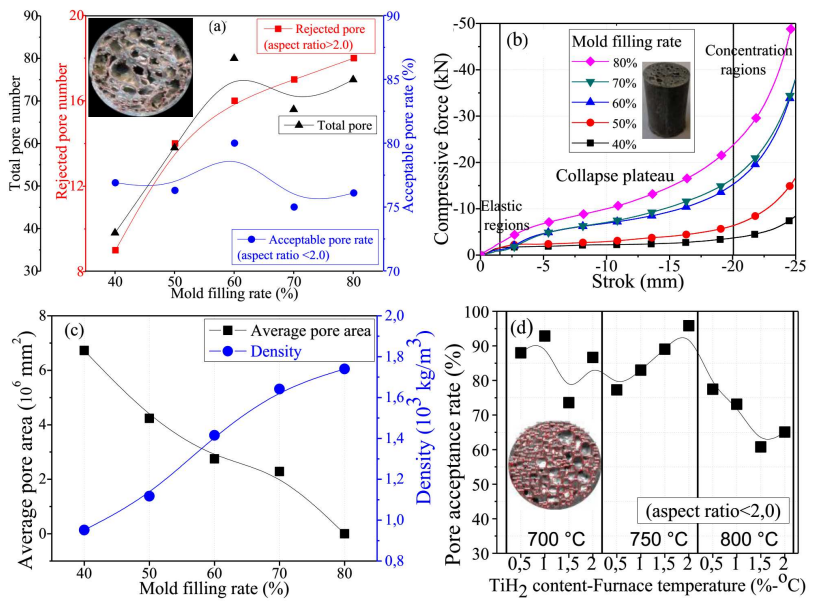

Fig. 4. Assessments of the obtained pores: (a) total, rejected and acceptable pores, (b) comparison of the crushing behavior, (c) average pore area and density values, (d) pore acceptance rate.

The crushing behavior under compressive loading was compared with metallic foams which were produced according to different mold filling ratio in Fig. 4b. The characteristic zones of metal foams under the compressive load are an elastic region, collapse plateau, and concentration regions which are indicated in Fig. 4b. The strength of the foam materials under the compressive load for five different mold filling ratio showed a regular increasing trend by considering the curves in Fig. 4b. Depending the mold filling rate on the average pore area and the density values were shown in Fig. 4c as a graphical representation. When mold filling ratio was increased towards $80 \%$ from 40 , it resulted in the decrease of the average pore area. On the contrary, it was understood that the density values were on an upward trend. As a result of the studies which were carried out for identifying the appropriate ratio, it was concluded that the most suitable mold filling rate is $60 \%$. The pore acceptance rate with different $\mathrm{TiH}_{2}$ contents at 3 different furnace temperature can be seen in Fig. 4d. The case of 1.0 aspect ratio value of a pore is the exact spherical situation. Pores having aspect ratios of below 2.0 were considered acceptable. In Fig. 4d, an unstable situation was detected between 700 and $800^{\circ} \mathrm{C}$ furnace temperature. Also, when the temperature was set at $750^{\circ} \mathrm{C}$ pore acceptance rate showed regular changes depending on the $\mathrm{TiH}_{2}$ content in Fig. 4d. It was concluded that $2 \mathrm{wt} \% \mathrm{TiH}_{2}$ content and $750^{\circ} \mathrm{C}$ furnace temperature should be set on closed cell $\mathrm{Al}$-foam production in the $\mathrm{PM}$ route according to 
the pore acceptance graph. The stable pore structure was achieved at $750^{\circ} \mathrm{C}$. Besides this findings, distortions were seen in the aspect ratio of the pores at $800^{\circ} \mathrm{C}$.

Cell structure and the cell wall of Al-foam manufactured using the novel process parameters were analyzed by scanning electron microscopy (Fig. 5a and b). The cell structure of the closed cell Al-foam cross-section can be seen in Fig. 5a. The pore radius distribution is determined in the range from 3 to $5 \mathrm{~mm}$ on the cross-section. Resulting cell structures were generally global, and polyhedral cells were also found. The two adjacent cells had a common wall. This wall holds three prismatic curves and inner face called the plateau region of a cell. These two cells bordered by a rod-like structure that surrounded the inner faces. The cell wall structure at a magnification of $100 \times$ can be shown in Fig. 5b. It is distinctly demonstrated that the foaming agent release hydrogen gas during the production process with the increasing temperature and the forming of $\mathrm{TiH}_{2}$ reaction on the inner wall surface is seen in Fig. 5b. According to SEM analysis, there were not any collapsing, cracking or delamination on the wall of obtained $\mathrm{Al}$ foams.

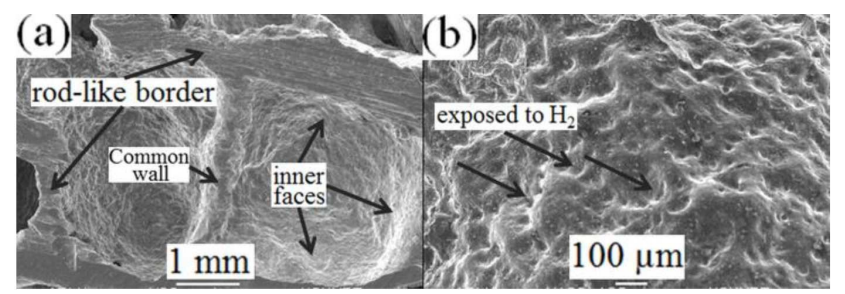

Fig. 5. Microstructures of the inner Al-foam cell: (a) $20 \times$, (b) $100 \times$.

\section{Conclusion}

As a result of the investigation on the effect of titanium hydride, it was concluded that the heat treatment must be implemented in the range of $450-500{ }^{\circ} \mathrm{C}$ to reach a stable foam structure. The original procedure performed for the mixing analysis that was shown at the $90 \mathrm{rpm}$ stirring rate, both of 90 and 120 min mixing times gave the desired result. The pressing analysis revealed that the most appropriate value for deformation of the surface oxide layer and the precursor preparation was $350 \mathrm{MPa}$ in the $\mathrm{PM}$ route for the production of closed cell Al-foam. The investigation of different mold filling rate mainly included pore analysis, as a result of that the most convenient rate was $60 \%$. Acceptance-rejection criteria used in pore analysis were original and a new approach for the metal foams. There was possible observing of the foaming reaction stages with borosilicate glass molding, which was tested for the first time at holding step in a furnace as an another originality of the work. Using a borosilicate glass molding technique was an entirely original system for production of closed cell metal foams in PM route. It was concluded that $2 \mathrm{wt} \%$ $\mathrm{TiH}_{2}$ content and $750^{\circ} \mathrm{C}$ furnace temperature should be set on closed cell Al-foam production in the PM route according to the pore acceptance graph.

\section{Acknowledgments}

The authors gratefully acknowledge the financial support rendered by the Scientific Research Projects Unit of Kocaeli University, Turkey (KOU-BAP, 2010/093).

\section{References}

[1] M.F. Ashby, A.G. Evans, N.A. Fleck, L.J. Gibson, J.W. Hutchinson, H.N.G. Wadley, Metal Foams: A Design Guide, Butterworth Heinemann, Woburn 2000.

[2] J. Banhart, Prog. Mater. Sci. 46, 559 (2001).

[3] F. Baumgärtner, I. Duarte, J. Banhart, Adv. Eng. Mater. 2, 168 (2000).

[4] F. Garcia-Moreno, J. Banhart, Coll. Surf. A 309, 264 (2007).

[5] I. Sridhar, N.A. Fleck, J. Mater. Sci. 40, 4005 (2005).

[6] B. Zettl, H. Mayer, S.E. Stanzl-Tschegg, Int. J. Fatigue 23, 565 (2001).

[7] V. Crupi, R. Montanini, Int. J. Impact Eng. 34, 509 (2007).

[8] A. Rabiei, A.T. O'Neill, Mater. Sci. Eng. A Struct. 404, 159 (2005).

[9] L.J. Vendra, A. Rabiei, Mater. Sci. Eng. A Struct. 465, 59 (2007)

[10] M. Malekjafarian, S.K. Sadrnezhaad, Mater. Des. 42, 8 (2012).

[11] E. Koza, M. Leonowicz, S. Wojciechowski, F. Simancik, Mater. Lett. 58, 132 (2003).

[12] L.Y. Aguirre-Perales, I.H. Jung, R.A.L. Drew, Acta Mater. 60, 759 (2012).

[13] D. Mandrino, I. Paulin, S.D. Skapin, Mater. Character. 72, 87 (2012).

[14] B.M. Lux, J. Banhart, S. Fiechter, O. Goerke, N. Wanderka, Acta Mater. 54, 1887 (2006). 